\title{
Production of oligomeric procyanidins by mild steam explosion treatment of grape seeds
}

\author{
Jie Zhang ${ }^{1,2 \dagger}$, Dan Liu ${ }^{1 \dagger}$, Aoke Wang ${ }^{1}$, Li Cheng ${ }^{1}$, Wenya Wang ${ }^{1,2^{*}}$ (D), Yanhui Liu', Sadeeq Ullah ${ }^{1}$ and \\ Qipeng Yuan ${ }^{1 *}$
}

\begin{abstract}
Background: Sixty five percent of procyanidins in grape seeds is polymeric procyanidins (PPC), and they could not be assimilated directly by human. To enhance procyanidin assimilation, steam explosion treatment (SE) was used to facilitate the preparation of oligomeric procyanidins (OPC) from grape seeds.

Results: The results indicate that SE treatment made grape seeds loose and porous, and decreased the mean degree of polymerization (MDP) of procyanidins. The procyanidins content and total phenolic content (TPC) were decreased with the increase of SE severity, while the amount of catechin (CA), epicatechin (EC) and epicatechin-3-O-gallate (ECG) were increased, resulting in significant increase of antioxidant activity.

Conclusions: Although SE treatment could depolymerize PPC and produce CA/EC/ECG with high yield, it caused the yield loss of total procyanidins. SE treatment is a potential effective method to prepare procyanidins with low degree of polymerization and high antioxidant activity. However, it still needs to study further how to balance the yield of total procyanidins and catechin monomers (CA/EC/ECG).
\end{abstract}

Keywords: Polymeric procyanidins, Oligomeric procyanidins, Steam explosion, Depolymerization, Antioxidant activities

\section{Introduction}

Grape pomace is the major solid residues from wine and grape juice industries, which mainly consist of grape seeds and skins (Silvan et al. 2020). Proanthocyanidins are distributing widely in skins and seeds of grape (Souquet et al. 1996; Prieur et al. 1994), and proanthocyanidins in grape seeds were procyanidin-type, consisting of catechin (CA) and epicatechin (EC) units, with partial galloylation (Porter 1988; Spranger et al. 2008). Procyanidins of grape seeds were constructed with C4-C8 linkages being much more abundant than C4-C6 bonds during

\footnotetext{
*Correspondence: wangwy@mail.buct.edu.cn; yuanqp@mail.buct.edu.cn ${ }^{\dagger}$ Jie Zhang and Dan Liu contribute to the work equally

${ }^{1}$ College of Life Science and Technology, Beijing University of Chemical Technology, Beijing 100029, China

Full list of author information is available at the end of the article
}

the polymerization of flavanol units (Monagas et al. 2010; Unusan 2020), and the degree of polymerization may be reached around 30 (Hayasaka et al. 2003; Spranger et al. 2008). Procyanidins show a wide biological activity, such as antivirus, radical scavenging, anti-oxidation and antitumor (Hümmer and Schreier 2010). Sixty five percent of procyanidins in grape seeds are polymeric procyanidins (PPC) with degree of polymerization (DP) $>4$ (Luo et al. 2018) and they could not be assimilated directly by human due to the higher degree of polymerization $(\mathrm{Ou}$ and Gu 2014). Therefore, if PPC could be depolymerized into oligomeric procyanidins (OPC), bioavailability and bioactivity of procyanidins could be increased significantly (Meeran and Katiyar 2007)

The available methods for depolymerizing PPC can be classified as: (1) acid hydrolysis with nucleophiles, such 
as phloroglucinol (Matthews et al. 1997) and benzyl mercaptane (Gu et al. 2002), while the depolymerizing reagents were not allowed to apply in food, pharmaceutical and cosmetic industry due to the toxicity of nucleophiles; (2) acid hydrolysis with expensive chain breakers, such as catechin (CA), epicatechin (EC), and epicatechin-3-Ogallate (ECG) (Liu et al. 2013); (3) acid hydrolysis with sulphurous acid, which produced the procyanidins with higher yield and purity, but its potential environmental impact is a big problem (Luo et al. 2018); (4) acid salt hydrolysis, such as sodium bisulfite, which also confronts the serious environmental problem (Lin et al. 2014); (5) alkaline hydrolysis, which only converted $6 \%$ of the PPC into OPC (White et al. 2010); (6) hydrogenolysis, which needs dangerous operating conditions and requires expensive catalysts ( $\mathrm{Li}$ et al. 2015). Taken together, the earlier reported methods indicated some drawbacks for their industrial applications, such as toxic byproducts, low hydrolyzing rate, dangerous operating conditions, high cost-consumption and environmental pollution (Wu et al. 2019). As a result, it is essential to develop an economic and environmental-friendly process for the production of OPC from PPC.

Steam explosion (SE) is an inexpensive and clean thermophysico-chemical process, including physical smash and chemical hydrolyzation (Jacquet et al. 2015). During steam explosion, the raw material was broken into pieces, and the micropores in original plant tissue were destroyed intensively (Chen and Chen 2011). Many natural products, such as flavonoids (Chen and Chen 2011; Qin and Chen 2015), total phenolic compounds (Gong et al. 2012; Serrano et al. 2017; Conde et al. 2009) and keratin (Zhang et al. 2015b), have been extracted with the aid of SE treatment. SE was used to increase the yield of flavonoids (quercitrin) by 8 times, and quercitrin was deglycosylated by cleavage of C-O bonds under SE treatment (Chen and Chen 2011). SE treatment could influence plant tissue in two ways: physical effect (destroying the structure of plant tissue) and chemical effect (chemical reaction at higher temperature including hydrolyzation, oxidation, pyrolysis, etc.) (Carvalheiro et al. 2008; Alvira et al. 2010). The physical effect could make the plant tissue loose and porous (larger cavities and intercellular spaces) by destroying the matrix of plant tissue, which could enhance the extracting rate of natural products (Carvalheiro et al. 2008; Alvira et al. 2010). The chemical effect could produce the natural products or release the natural products from their conjugates by the cleavage of the chemical bonds (Carvalheiro et al. 2008; Alvira et al. 2010). After the plant tissue was treated by SE, the resultant extracts depend on operating conditions: in the case of hemicellulose, mild SE conditions favour recovery of the longer chain structures, while more severe conditions facilitate the formation of monomers and their degradation products (Wojtasz-Mucha et al. 2017). Since natural products were usually sensitive to higher temperature and longer time at higher temperature, mild SE was suitable for plant tissues pretreatment during preparation of natural products.

In the present paper, mild SE treatment was used to facilitate the extraction of oligomeric procyanidins from grape seeds. The extracting conditions and antioxidant activity of procyanidins were investigated. The optimum SE operating conditions were determined. Finally, the depolymerization mechanism of procyanidin under SE treatment was suggested.

\section{Materials and methods}

\section{Chemicals and raw material}

CA and Folin - Ciocalteu phenol reagent were purchased from Sigma-Aldrich Chemical Co, Ltd, (St. Louis, MO, USA). EC, ECG, procyanidin B1, procyanidin B2 were purchased from Chengdu Manset Biotechnology Co, Ltd, (Chengdu, Sichuan, China). Procyanidin B3 and procyanidin C1 were purchased from Shanghai yuanye Bio-Technology Co, Ltd, (Shanghai, China). Cinnamtannin A2 was purchased from Shanghai ZZBIO Co, Ltd, (Shanghai, China). Gallic acid (GA), 2-20-azino-di-(3-ethylbenzthiazoline sulfonic acid) (ABTS) were purchased from TCI (Shanghai) Development Co, Ltd, (Shanghai, China). Vanillin, benzyl mercaptane, 2,2-diphenyl-1-picrylhydrazyl hydrate (DPPH) and 6-hydroxy-2,5,7,8-tetramethylchroman-2-carboxylic acid (Trolox) were purchased from Shanghai Macklin Biochemical Co, Ltd, (Shanghai, China). T-AOC Assay Kit was provided by Beyotime Biotechnology Co, Ltd, (Shanghai, China). Unless stated otherwise, the solvents used for chromatography were of high-performance liquid chromatography grade (HPLCgrade) and the other chemicals were of analytical reagent grade (AR-grade). Water was purified using a Milli-Q water purification system (Milford, MA, USA).

Grape seeds of "Chardonnay" were purchased from Xi'an Haoxuan Biotechnology Co, Ltd. The grape seeds were washed with deionized water for 3 times, then they were ground into powder by a high-speed blender and freeze-dried at $-40{ }^{\circ} \mathrm{C}$ in a vacuum freeze drier (SCIENTZ-18 N, Sunway Hanguang Electric Manufacturing Limited, Ningbo, China). The freeze-dried powder of grape seeds was sieved with a 20 -mesh sieve, then sealed with $\mathrm{N}_{2}$ and kept in $-20{ }^{\circ} \mathrm{C}$ for further experiments.

\section{Steam explosion pretreatment, structural observation and procyanidins extraction}

SE was carried out according to Zhang et al (2014). $100 \mathrm{~g}$ of freeze-dried grape seeds powder was mixed with $200 \mathrm{~mL}$ deionized water and the mixture was kept 
for $60 \mathrm{~min}$ at room temperature. The mixture was put into the SE equipment and pretreated at the combination of different pressures $(0.3,0.6,0.9,1.2$ or $1.5 \mathrm{MPa})$ and different time-courses ( $30 \mathrm{~s}$ or $60 \mathrm{~s}$ ), and then the pressure was reduced abruptly to atmospheric pressure. After SE, the pretreated grape seeds were collected and freeze-dried.

The unexploded and exploded samples were treated by dehydration, drying and coating with gold. Then, these samples were analyzed by scanning electron microscopy (SEM), (Japan Electronics Co, Ltd, Japan), which was operated at an accelerating voltage of $15 \mathrm{kV}$.

The extracting process of procyanidins was modified according to previous reports (Gu et al. 2002; Hellström and Mattila 2008). Two grams of freeze-dried unexploded and exploded samples were weighed. Then, they were defatted for $12 \mathrm{~h}$ with $20 \mathrm{~mL}$ hexane in $50 \mathrm{~mL}$ centrifuge tubes. After centrifugation at $9000 \mathrm{rpm}$ for $10 \mathrm{~min}$, the supernatants were discarded. The centrifuge tubes were placed into fume hood for $12 \mathrm{~h}$ to remove residual hexane. One gram of defatted samples was mixed with $10 \mathrm{~mL}$ of acetone/water/acetic acid (70/29.5/0.5, v/v/v) mixture in a $50 \mathrm{~mL}$ centrifuge tubes. The tubes were vortexed for $30 \mathrm{~s}$, and then kept at $37{ }^{\circ} \mathrm{C}$ for $10 \mathrm{~min}$ with ultrasound treatment. Procyanidins were extracted for $50 \mathrm{~min}$ at ambient temperature under $300 \mathrm{rpm}$ shaking. After centrifugation at $9000 \mathrm{rpm}$ for $15 \mathrm{~min}, 7.5 \mathrm{~mL}$ supernatants were pipetted out and filtered using a polypropylene filter membrane $(0.45 \mu \mathrm{m})$ for further analysis.

\section{Procyanidins content assessment}

Procyanidins content assay was modified according to previous reports (Çam and Hışıl 2010), using an ultraviolet-visible V-5100B spectrophotometer (Shanghai Metash Instruments Co, Ltd, China). One milliliter of 60 -fold diluted extract was first mixed with $2.5 \mathrm{~mL}$ of $1 \%$ vanillin in methanol solution, and then mixed with $2.5 \mathrm{~mL}$ of $25 \% \mathrm{H}_{2} \mathrm{SO}_{4}$ in methanol solution. After keeping in water bath at $30{ }^{\circ} \mathrm{C}$ for $15 \mathrm{~min}$, the absorbance of mixtures was read at $500 \mathrm{~nm}$. Pure methanol was used as a blank. CA was used as a standard control, and the calibration curve has a good linear relationship at the range: $10-100 \mu \mathrm{g} / \mathrm{mL}\left(R^{2}=0.9998\right)$. According to a calibration curve, the results were described as catechin equivalents $(\mathrm{CE})(\mu \mathrm{g}$ CA /g dry matter $(\mathrm{DM}))$.

\section{Total phenolic content (TPC) assessment}

TPC was determined according to the early-reported method (Xu et al. 2014) using an ultraviolet-visible V-5100B spectrophotometer (Shanghai Metash Instruments Co, Ltd, China). One hundred microliters of 40 -fold diluted extracts were placed into $50 \mathrm{~mL}$ centrifuge tubes. Subsequently, $3900 \mu \mathrm{L}$ of distilled water,
$250 \mu \mathrm{L}$ of $2 \mathrm{~mol} / \mathrm{L}$ Folin-Ciocalteau reagent and $750 \mu \mathrm{L}$ of $20 \% \mathrm{Na}_{2} \mathrm{CO}_{3}$ were added. The mixtures were kept in water bath for $15 \mathrm{~min}$ at $30{ }^{\circ} \mathrm{C}$. Then, the absorbance of mixtures was read at $760 \mathrm{~nm}$. Pure methanol was used as a blank control, gallic acid was used as a standard control and the calibration curve has a good linear relationship at the range: $100-800 \mu \mathrm{g} / \mathrm{mL}\left(R^{2}=0.9999\right)$. According to a calibration curve, the final results were described as gallic acid equivalents (GAE) ( $\mu \mathrm{g}$ GA/g DM).

\section{Mean degree of polymerization (mDP) assessment}

The thiolysis of procyanidins was modified according to previous paper (Gu et al. 2002). Fifty microliters of extracts were mixed first with $50 \mu \mathrm{L} 3.3 \% \mathrm{HCl}$ in methanol solution in a $250-\mu \mathrm{L}$ polypropylene insert, and then $100 \mu \mathrm{L} 5 \%$ benzylmercaptan in methanol were added. The $250-\mu \mathrm{L}$ polypropylene insert was placed into a 1.5 $\mathrm{mL}$ vial and the vial was quickly sealed with a cap. The mixtures were kept in water bath at $40{ }^{\circ} \mathrm{C}$ for $30 \mathrm{~min}$, and then reacted at room temperature for $10 \mathrm{~h}$ for complete degradation. The final mixtures were kept at -20 ${ }^{\circ} \mathrm{C}$ and measured by reversed phase high performance liquid chromatography (RP-HPLC). Thiolysis products of procyanidin $\mathrm{B} 1$, procyanidin $\mathrm{B} 3$, and the $\mathrm{CA}$, CA benzylthioether, the EC, EC benzylthioether were used as standards to identify their counterparts (Furuuchi et al. 2011). Standard solutions for CA, EC, ECG, procyanidin dimers $\mathrm{B} 1$ and procyanidin dimers $\mathrm{B} 3$ were prepared at $1000 \mu \mathrm{g} / \mathrm{mL}$.

Chromatographic analysis was modified according to previous papers (Gu et al. 2002). HPLC analysis was performed using a Shimadzu LC-20AT (Shimadzu, Japan) equipped with a UV-detector, a binary pump, an auto-sampler and a column compartment. Separation was carried out using a Diamonsil C18 column $(5 \mu \mathrm{m}$, $250 \times 4.6 \mathrm{~mm}$ i.d.) from Dikma Technologies (Beijing, China). The detection wavelength and column temperature were set at $280 \mathrm{~nm}$ and $35{ }^{\circ} \mathrm{C}$. The mobile phases were the mixture of solvent A (water/acetic acid =98/2) and solvent B (methanol, 100\%), which was developed as $0 \min (\mathrm{A}=85 \%, \mathrm{~B}=15 \%) \rightarrow 45 \min (\mathrm{A}=20 \%$, $\mathrm{B}=80 \%) \rightarrow 50 \quad \min \quad(\mathrm{A}=20 \%, \quad \mathrm{~B}=80 \%) \rightarrow 55 \quad \mathrm{~min}$ $(\mathrm{A}=85 \%, \mathrm{~B}=15 \%) \rightarrow 70 \min (\mathrm{A}=85 \%, \mathrm{~B}=15 \%)$. The flow rate was set at $1.0 \mathrm{~mL} / \mathrm{min}$ and the injection volume was set as $20 \mu \mathrm{L}$. Then, standard solutions were used to identify and quantify the samples. Although the presence of EGC-thiol and ECG-thiol was ignored in the early reports for mDP calculation (Furuuchi et al. 2011), their peaks were included in the present paper to increase the accuracy of the $\mathrm{mDP}$ calculation. The $\mathrm{mDP}$ of extracts can be calculated with the Eq. (1): 


$$
\mathrm{mDP}=\frac{\text { Total area ratio of extension units benzlthioether }}{\text { Total area ratio of terminal units }}+1
$$

\section{Measurements of antioxidant activity}

DPPH. radical-scavenging capacity, ferric reducing power and $\mathrm{ABTS}_{\bullet}{ }^{+}$radical-scavenging capacity were used to analyze the antioxidant activity of extracts. Diluted extract was prepared at same concentration $(\mu \mathrm{g}$ CA/g DM).

The DPPH assay was modified according to the reported papers (Xu et al. 2014). One hundred microliters of diluted extracts were placed into the tube. Then, $3900 \mu \mathrm{L}$ of $25 \mu \mathrm{g} / \mathrm{mL}$ DPPH in methanol solution was added. The mixtures were kept in water bath for $60 \mathrm{~min}$ at $30{ }^{\circ} \mathrm{C}$ in darkness. Finally, the absorbance of mixtures was read at $515 \mathrm{~nm}$. The scavenging capacity of diluted extracts on DPPH can be calculated with the following equation:

$$
\text { Scavenging rate }=\frac{\left(\mathrm{A}_{0}-\mathrm{A}\right)}{\mathrm{A}_{0}} \times 100(\%)
$$

where $A_{0}$ was the absorbance of blank control (methanol solution); A was the absorbance of the diluted extracts. Trolox was used as a standard control, and the calibration curve has a good linear relationship between scavenging rate and concentration of Trolox solutions at the range: $100-1000 \mu \mathrm{mol} / \mathrm{L}\left(R^{2}=0.9996\right)$. According to a calibration curve, the final radical scavenging activities were described as Trolox equivalent (TE) ( $\mu \mathrm{mol} \mathrm{T} / \mathrm{g} \mathrm{DM})$.

The FRAP assay was carried out with a T-AOC Assay Kit (Xia et al. 2017). The experiments of the FRAP assay was performed in 96-well polystyrene microplates. Pure methanol solution was used as a blank control. Trolox was used as a standard control, and the calibration curve indicated a significant linear relationship between ferric reducing power and concentration of Trolox solutions at the range: $150-1500 \mu \mathrm{mol} / \mathrm{L}\left(R^{2}=0.9983\right)$. According to a calibration curve, the final ferric reducing power was described as TE ( $\mu$ mol T/g DM).

The ABTS assay was carried out according to early reports (Oldoni et al. 2016). The $7 \mathrm{mmol} / \mathrm{L}$ ABTS and $140 \mathrm{mmol} / \mathrm{L}$ potassium persulfate were reacted for forming ABTS ${ }^{+}$radical at $25{ }^{\circ} \mathrm{C}$ in darkness for $12 \mathrm{~h}$. To get absorbance value of 0.70 at $734 \mathrm{~nm}$, the prepared ABTS ${ }^{+}{ }^{+}$radical solution was diluted with ethanol. Thirty microliters of diluted extracts were mixed with $3.0 \mathrm{~mL}$ of the diluted ABTS ${ }^{+}$radical solution and kept at $30{ }^{\circ} \mathrm{C}$ in darkness for $6 \mathrm{~min}$. At the end, absorbance of mixture was measured at $734 \mathrm{~nm}$. Pure ethanol was as a blank. The radical scavenging capacity of the diluted extracts on $\mathrm{ABTS}^{+}{ }^{+}$can be calculated with the following equation:
Scavenging rate $=\frac{\left(\mathrm{A}_{0}-\mathrm{A}\right)}{\mathrm{A}_{0}} \times 100(\%)$

where $A_{0}$ was the absorbance of blank; A was the absorbance of diluted extracts. Trolox was used as a standard control, and the calibration curve has a good linear relationship between scavenging rate and concentration of Trolox solutions at the range: $100-2000 \mu \mathrm{mol} / \mathrm{L}$ $\left(R^{2}=0.9959\right)$. According to calibration curve, the final radical scavenging activities was described as TE $(\mu \mathrm{mol}$ T/g DM).

\section{NP-HPLC analysis of procyanidins}

Chromatographic analysis was modified according to the early paper (Choy et al. 2013). Normal phase high performance liquid chromatography (NP-HPLC) analysis was carried out by a Shimadzu LC-20AT (Shimadzu, Japan). Separation was carried out on a Develosildiol 100 column $(5 \mu \mathrm{m}, 250 \times 4.6 \mathrm{~mm}$ i.d. $)$ from Nomura Chemical Co, Ltd, (Japan). The mobile phase was the mixture of solvent A (acetonitrile/water $=98 / 2, \mathrm{v} / \mathrm{v}$ ) and solvent $\mathrm{B}$ (methanol/water/acetic acid $=95 / 3 / 2, \mathrm{v} / \mathrm{v} / \mathrm{v}$ ). The gradient elution program was developed as: $0 \mathrm{~min}(\mathrm{~A}=93 \%$, $\mathrm{B}=7 \%) \rightarrow 3 \min (\mathrm{A}=93 \%, \mathrm{~B}=7 \%) \rightarrow 53 \mathrm{~min}(\mathrm{~A}=62.4 \%$, $\mathrm{B}=37.6 \%) \rightarrow 56 \quad \min \quad(\mathrm{A}=0 \%, \quad \mathrm{~B}=100 \%) \rightarrow 69 \min$ $(\mathrm{A}=0 \%, \mathrm{~B}=100 \%) \rightarrow 75 \mathrm{~min}(\mathrm{~A}=93 \%, \mathrm{~B}=7 \%) \rightarrow 85 \mathrm{~min}$ $(A=93 \%, B=7 \%)$. The flow rate was $1.0 \mathrm{~mL} / \mathrm{min}$ and the injection volume was $20 \mu \mathrm{L}$. The detection wavelength and column temperature were set at $280 \mathrm{~nm}$ and $30{ }^{\circ} \mathrm{C}$. The peaks of procyanidins with different DP were assigned by comparing retention time with the standards (Additional file 1: Table S1) (Choy et al. 2013). Standard solutions of CA, EC, ECG, procyanidin B1, procyanidin $\mathrm{B} 2$, procyanidin $\mathrm{B} 3$, procyanidin $\mathrm{C} 1$ and Cinnamtannin A2 were prepared with concentration of $1000 \mu \mathrm{g} / \mathrm{mL}$. The solutions of the standards were filtered using a polypropylene filter membrane $(0.45 \mu \mathrm{m})$. One milliliter of $1 \mathrm{mg} / \mathrm{mL}$ CA, EC, ECG standards were mixed in screwed glass tubes to get procyanidin standards 1 . One milliliter of $1 \mathrm{mg} / \mathrm{mL}$ procyanidin $\mathrm{B} 1$, procyanidin $\mathrm{B} 2$, procyanidin B3 standards were mixed to get procyanidin standards 2. One milliliter of $1 \mathrm{mg} / \mathrm{mL}$ CA, EC, ECG, procyanidin $\mathrm{B} 1$, procyanidin $\mathrm{B} 2$, procyanidin $\mathrm{B} 3$, procyanidin $\mathrm{C} 1$ and innamtannin A2 standards were mixed to get procyanidin standards 3. Standard solutions were used to quantify chemicals. Peak area growth ratio of procyanidins (RAGR) with different DP can calculated with the following equation:

$$
\mathrm{RAGR}=\frac{\mathrm{A}_{\mathrm{s}-\mathrm{n}}}{\mathrm{A}_{\mathrm{u}-\mathrm{n}}}(\mathrm{n}=1, \mathrm{ECG}, 2,3,4, \geq 5)
$$


where $A_{s-n}$ was peak area of steam-exploded procyanidins with $\mathrm{DP}=\mathrm{n} ; \mathrm{A}_{\mathrm{u}-\mathrm{n}}$ was peak area of unexploded procyanidins with $\mathrm{DP}=\mathrm{n}$.

\section{Statistical analysis}

Statistical analysis was carried out with Origin 2017. Means were calculated using one sample $t$-Test. Significance level was set at $\mathrm{P} \leq 0.05$.

\section{Results and discussion}

\section{Effects of SE treatment on grape seed structure and procyanidins content}

The SEM micrographs of exploded and unexploded grape seeds are shown in Fig. 1a. From top to bottom, the SE pressures were varied from 0 to $1.5 \mathrm{MPa}$. From left to right, the operating time was kept for $30 \mathrm{~s}$ or $60 \mathrm{~s}$. The SEM micrographs indicated the difference between the unexploded and exploded grape seeds. After the SE treatment, grape seeds became loose and porous, resulting in the larger cavities and more intercellular spaces (Wang et al. 2016).

However, Fig. 1b indicates that SE treatment did not increase the yield of procyanidins, but decreased the yield. It has been reported that the increase of SE severity decreased flavonoids yield due to procyanidins degradation (Qin and Chen 2015). When the pressure was increased from 0 to $1.5 \mathrm{MPa}$ for $30 \mathrm{~s}$ or $60 \mathrm{~s}$, the procyanidins content decreased from 96.12 to $28.37 \mu \mathrm{g} \mathrm{CA} / \mathrm{g}$ DM or 96.12 to $26.35 \mu \mathrm{g}$ CA /g DM, respectively. To evaluate whether the procyanidins were converted into other phenolic compounds or not, the TPC was measured and results are shown in Fig. 1c. The results indicated that TPC decreased significantly with the increase of severity, which did not agree with the reported results from barley bran (Gong et al. 2012). When the pressure increased from 0 to $1.5 \mathrm{MPa}$ for $30 \mathrm{~s}$ or $60 \mathrm{~s}$, the TPC decreased from 285.34 to $177.73 \mu \mathrm{g}$ CA /g DM or 285.34 to $161.91 \mu \mathrm{g}$ CA /g DM, respectively. The possible reason might be attributed to structural difference of plant

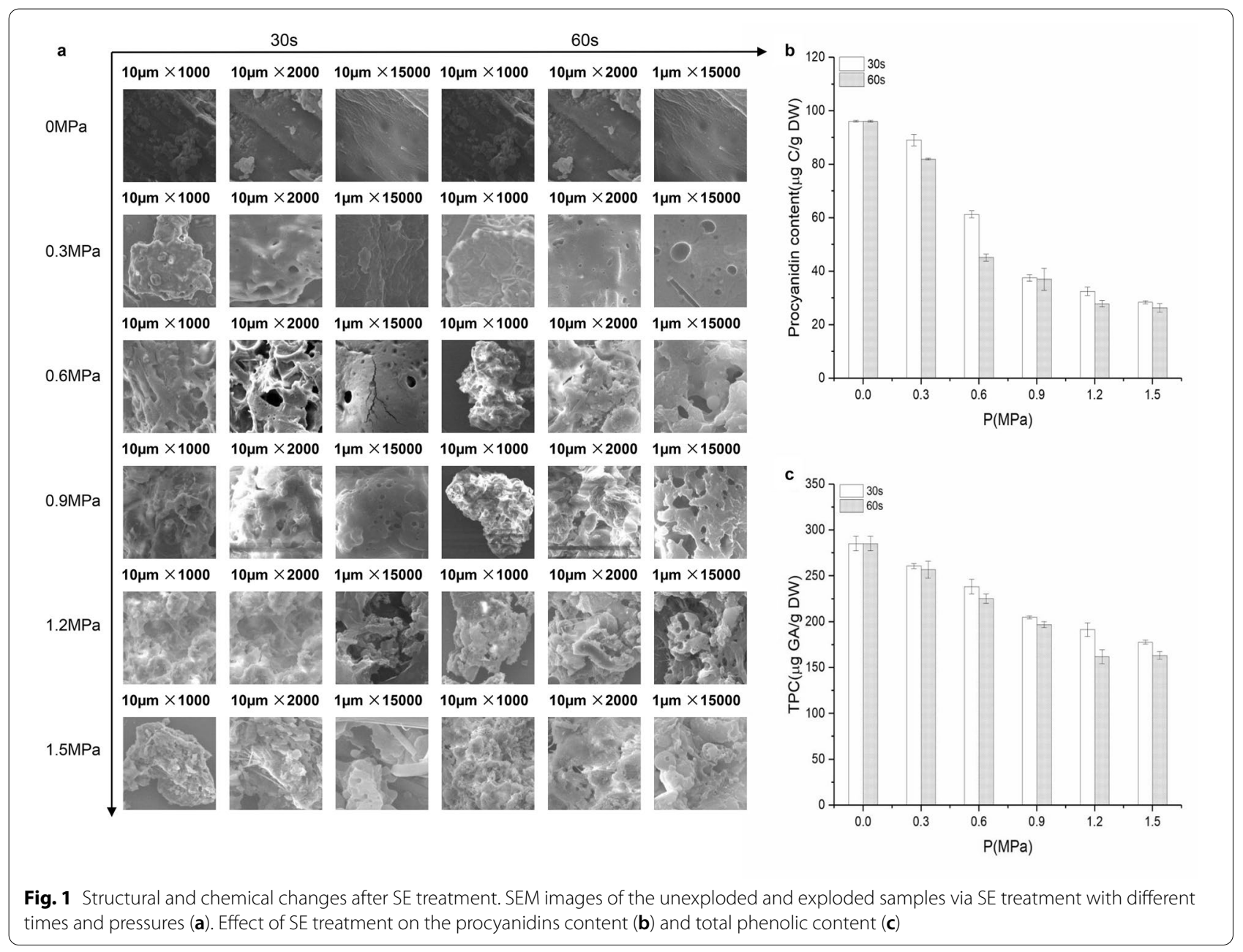


(See figure on next page.)

Fig. 2 RP-HPLC chromatogram of thiolysed crude extract of unexploded grape seeds (a); terminal units: b CA (1), c EC (2), d ECG (3); e benzylmercaptan (9); extension units: $\mathbf{f}$ EC-thiol (7); $\mathbf{g} \beta$-CA-thiol (4), a-CA-thiol (6)

tissues and phenolic compounds between barley bran and grape seeds, and the phenolic compounds in grape seeds might be more sensitive to SE treatment. Although the results couldn't explain the reason of procyanidins loss, they indeed proved that the SE treatment could affect the yield of procyanidins. Therefore, the effect of SE treatment on procyanidins polymerization was investigated further.

\section{Effect of SE treatment on mean degree of polymerization (mDP) and antioxidant activity}

Thiolysis was used to analyze the structure of procyanidins in different SE treatment conditions. In thiolysis reactions, the extension units of procyanidins were attacked by benzyl mercaptan to form benzylthioether, while the terminal units were released as a free procyanidin unit without the linkage of benzylthioether (Fig. 2a) (Gu et al. 2002). Among the thiolysis residues of procyanidins of grape seeds, 3,4-trans-catechin benzylthioether ( $\beta$-CA-thiol), 3,4-cis-catechin benzylthioether ( $\alpha$-CAthiol), 3,4-trans-epicatechin benzylthioether (EC-thiol), (epi) gallocatechin benzylthioether (EGC-thiol) and epicatechin-3-O-gallate benzylthioether (ECG-thiol) were derived from extension units, and CA, EC and ECG belonged to terminal units (Fig. 2), which agreed with earlier reports (Bordiga et al. 2011; Vivas et al. 2004). They were all identified, assigned and quantified with reference material and documents (Ito et al. 2013; Hellström and Mattila 2008) (Fig. 2, Additional file 1: Table S2).

Table 1 indicates that terminal unites of procyanidins from grape-seeds' extract consisted of CA, EC and ECG, and the extension unites included CA, ECG, EC, EGC. The $\mathrm{mDP}$ was ranging from 5.03 to 1.97 with the increase of pressure and treating time, which indicated the negative relationship between $\mathrm{mDP}$ and SE severity. On the basis of the above results, it was indicated that the $\mathrm{SE}$ treatment could effectively depolymerize PPC into OPC.

It has been reported that OPC showed higher antioxidant activity in vitro or in vivo (Sun et al. 2011; Zhang et al. 2015a). The antioxidant activities of the procyanidins were found to be in a decreasing order: procyanidin $\mathrm{C} 1>$ procyanidin $\mathrm{B} 2-3^{\prime}$-O-gallate $>$ procyanidin $\mathrm{B} 2>$ procyanidin $\mathrm{B} 1>\mathrm{ECG}>\mathrm{EC}>\mathrm{CA}>$ Trolox ( $\mathrm{Li}$ et al. 2016; Luo et al. 2016). Furthermore, the antioxidant activities of procyanidins increased with the decrease of DP. Thus, the antioxidant activities of the different samples were analyzed by DPPH, ABTS and FRAP assay, which were described with TE (Fig. 3a, c, e). The antioxidant activities of SE-treated samples all increased significantly in comparison with the unexploded one. However, there was no positive relationship between the SE severity and antioxidant capacity, the higher correlations were found between antioxidant activity and $\mathrm{mDP}$ (Fig. 3b, d, f), with the correlation coefficient varying between 0.90247 and $0.99994(P<0.05)$. Moreover, the antioxidant activity was highly positively correlated with $\mathrm{mDP}$ value. The maximum antioxidant activity of DPPH, FRAP and ABTS assays were obtained at $1.2 \mathrm{MPa} / 30 \mathrm{~s}(368.00,394.33$, $645.96 \mu \mathrm{mol} \mathrm{T} / \mathrm{g} \mathrm{DM})$ and $0.9 \mathrm{MPa} / 60 \mathrm{~s}(340.65,404.22$, $623.24 \mu \mathrm{mol} \mathrm{T} / \mathrm{g} \mathrm{DM})$.

\section{Identification of procyanidin components after SE treatment by NP-HPLC}

Chromatographic analysis was performed on the basis of the reported method (Choy et al. 2013) with the exception of replacing the fluorescence detectors with UV detectors. Although fluorescent detector was very sensitive for procyanidins analysis, the relative response factors of procyanidins with UV detector showed a better result (Chen et al. 2009).

Since only solubilized procyanidins in the aqueous phase, such as OPC, are bio-accessible for the enterocyte surface of the small intestine (Ou and $\mathrm{Gu} 2014$ ), it is necessary to investigate whether the SE treatment could facilitate the depolymerization of PPC, and it is also important to analyze the OPC components after SE treatments. NP-HPLC was applied for procyanidins analysis. Initially, the mobile phase was performed according to Choy's reports (2013), and the resultant chromatogram indicated that there existed a peak with a big area at $62.2 \mathrm{~min}$, which is also peak position of procyanidins of $\mathrm{DP}>10$; thus, the operating conditions significantly influenced the measure of procyanidins of DP $>10$ (Fig. 4b, c). Nevertheless, when acetic acid in solvent A was replaced by water, the big peak at 62.2 min was reduced substantially, and the measurement of procyanidins with $\mathrm{DP} \leq 9$ were not affected (Fig. 4b, c, Additional file 1: Table S1). As a result, the solvent A was modified as acetonitrile/ water $(98 / 2, \mathrm{v} / \mathrm{v})$. The assignments of the peaks in grapeseeds' extract were accomplished by comparing their retention time with standards (CA, EC, ECG and procyanidin B1, B2, B3, C1, Cinnamtannin A2) (Additional file 1: Fig. S1a-g) and mixed standards (Additional file 1: Fig. S1h, i) and referring to published data (Additional file 1: Table S2) (Ito et al. 2013; Hellström and Mattila 2008). 


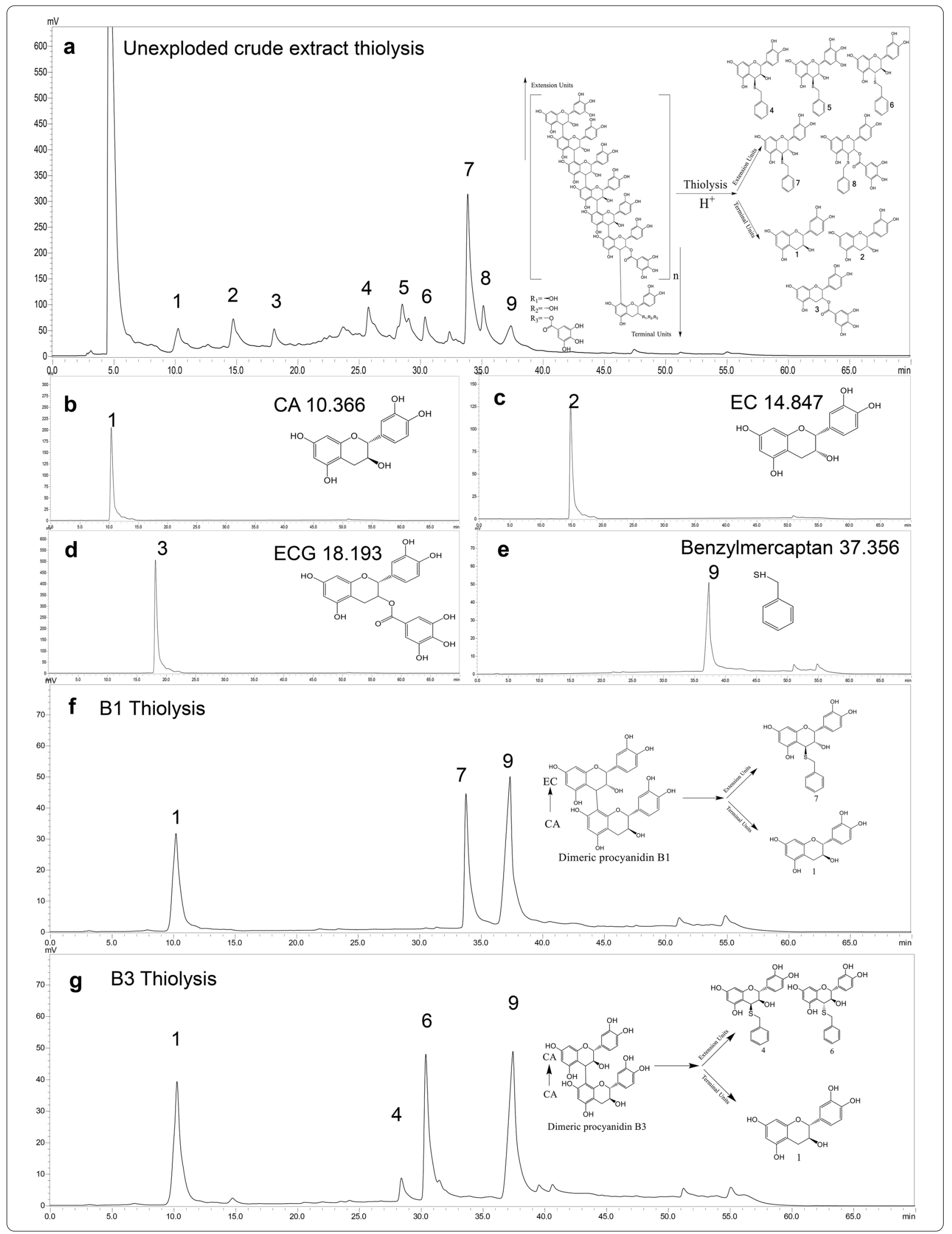


Table 1 mDP of grape seeds procyanidins after SE treatments

\begin{tabular}{|c|c|c|c|c|c|c|c|c|c|c|}
\hline \multirow[t]{2}{*}{$P$} & \multirow[t]{2}{*}{$\mathrm{T}$} & \multicolumn{4}{|c|}{ Terminal units (\%) } & \multicolumn{4}{|c|}{ Extension units (\%) } & \multirow[t]{2}{*}{$\mathrm{mDP}$} \\
\hline & & CA & EC & ECG & $\beta-C A$ & EGC & EC & ECG & $\mathrm{a}-\mathrm{CA}$ & \\
\hline \multirow[t]{2}{*}{0} & - & $2.15 \pm 0.02 a$ & $2.70 \pm 0.01 a$ & $1.26 \pm 0.00 \mathrm{a}$ & $5.10 \pm 0.01 a$ & $3.69 \pm 0.01 a$ & $10.21 \pm 0.01 a$ & $2.67 \pm 0.01 a$ & $2.89 \pm 0.01 a$ & $5.03 \pm 0.00 \mathrm{a}$ \\
\hline & - & $2.15 \pm 0.02 \mathrm{a}$ & $2.70 \pm 0.01 a$ & $1.26 \pm 0.00 \mathrm{a}$ & $5.10 \pm 0.01 a$ & $3.69 \pm 0.01 a$ & $10.21 \pm 0.01 a$ & $2.67 \pm 0.01 a$ & $2.89 \pm 0.01 \mathrm{a}$ & $5.03 \pm 0.00 \mathrm{a}$ \\
\hline \multirow[t]{2}{*}{0.3} & 30 & $3.31 \pm 0.01 \mathrm{c}$ & $3.31 \pm 0.01 c$ & $2.61 \pm 0.01 \mathrm{c}$ & $1.50 \pm 0.01 \mathrm{c}$ & $0.64 \pm 0.01 c$ & $19.27 \pm 0.01 b$ & $9.50 \pm 0.01 b$ & $3.37 \pm 0.01 c$ & $4.72 \pm 0.01 b$ \\
\hline & 60 & $3.38 \pm 0.01 c$ & $3.50 \pm 0.01 b$ & $2.81 \pm 0.01 \mathrm{c}$ & $1.48 \pm 0.01 \mathrm{c}$ & $0.61 \pm 0.01 \mathrm{c}$ & $20.29 \pm 0.02 c$ & $9.45 \pm 0.00 b$ & $3.10 \pm 0.01 c$ & $4.61 \pm 0.00 b$ \\
\hline \multirow[t]{2}{*}{0.6} & 30 & $2.99 \pm 0.01 \mathrm{c}$ & $2.45 \pm 0.01 \mathrm{c}$ & $1.82 \pm 0.01 \mathrm{c}$ & $3.86 \pm 0.02 b$ & - & $10.83 \pm 0.01 b$ & $5.12 \pm 0.01 b$ & $5.40 \pm 0.00 \mathrm{~b}$ & $4.47 \pm 0.01 b$ \\
\hline & 60 & $3.35 \pm 0.01 c$ & $2.33 \pm 0.00 c$ & $1.69 \pm 0.01 \mathrm{c}$ & $2.16 \pm 0.01 \mathrm{c}$ & - & $7.71 \pm 0.01 c$ & $3.03 \pm 0.01 c$ & $4.60 \pm 0.01 b$ & $3.37 \pm 0.00 c$ \\
\hline \multirow[t]{2}{*}{0.9} & 30 & $1.97 \pm 0.01 \mathrm{C}$ & $1.60 \pm 0.00 c$ & $1.05 \pm 0.01 \mathrm{c}$ & $0.80 \pm 0.01 c$ & $0.27 \pm 0.02 c$ & $5.40 \pm 0.00 b$ & $1.92 \pm 0.02 c$ & $2.13 \pm 0.02 c$ & $3.27 \pm 0.01 c$ \\
\hline & 60 & $2.59 \pm 0.01 \mathrm{c}$ & $1.69 \pm 0.01 \mathrm{C}$ & $1.05 \pm 0.01 c$ & $0.97 \pm 0.01 c$ & - & $3.16 \pm 0.01 c$ & $1.05 \pm 0.01 \mathrm{c}$ & $2.59 \pm 0.01 \mathrm{C}$ & $2.46 \pm 0.01 c$ \\
\hline \multirow[t]{2}{*}{1.2} & 30 & $2.05 \pm 0.01 b$ & $1.27 \pm 0.01 c$ & $0.72 \pm 0.00 c$ & $0.63 \pm 0.01 c$ & - & $1.33 \pm 0.02 c$ & $0.31 \pm 0.01 \mathrm{c}$ & $1.64 \pm 0.02 c$ & $1.97 \pm 0.01 c$ \\
\hline & 60 & $1.63 \pm 0.01 c$ & $1.13 \pm 0.01 \mathrm{c}$ & $0.61 \pm 0.00 c$ & $0.62 \pm 0.01 c$ & - & $1.35 \pm 0.01 c$ & $0.59 \pm 0.01 \mathrm{c}$ & $1.13 \pm 0.02 c$ & $2.10 \pm 0.00 c$ \\
\hline \multirow[t]{2}{*}{1.5} & 30 & $1.69 \pm 0.01 c$ & $1.25 \pm 0.01 c$ & $0.63 \pm 0.01 c$ & $0.35 \pm 0.01 c$ & - & $2.28 \pm 0.01 c$ & $0.79 \pm 0.02 c$ & $0.93 \pm 0.02 c$ & $2.22 \pm 0.03 c$ \\
\hline & 60 & $1.58 \pm 0.01 c$ & $1.21 \pm 0.01 c$ & $0.65 \pm 0.00 c$ & $0.38 \pm 0.01 c$ & - & $2.62 \pm 0.01 c$ & $0.90 \pm 0.01 c$ & $1.02 \pm 0.01 c$ & $2.43 \pm 0.01 c$ \\
\hline
\end{tabular}

$P$ Pressure (MPa), $T$ Time of steam-explosion treatment (s). The results are described as the means \pm standard deviation ( $n=3)$. Means in the same column with different letters indicate significant differences, which were determined by One sample $t$-Test. (c:significance at $P<0.01 ;$ b:significance at $P<0.05$; a:significance at $P>0.05$.)
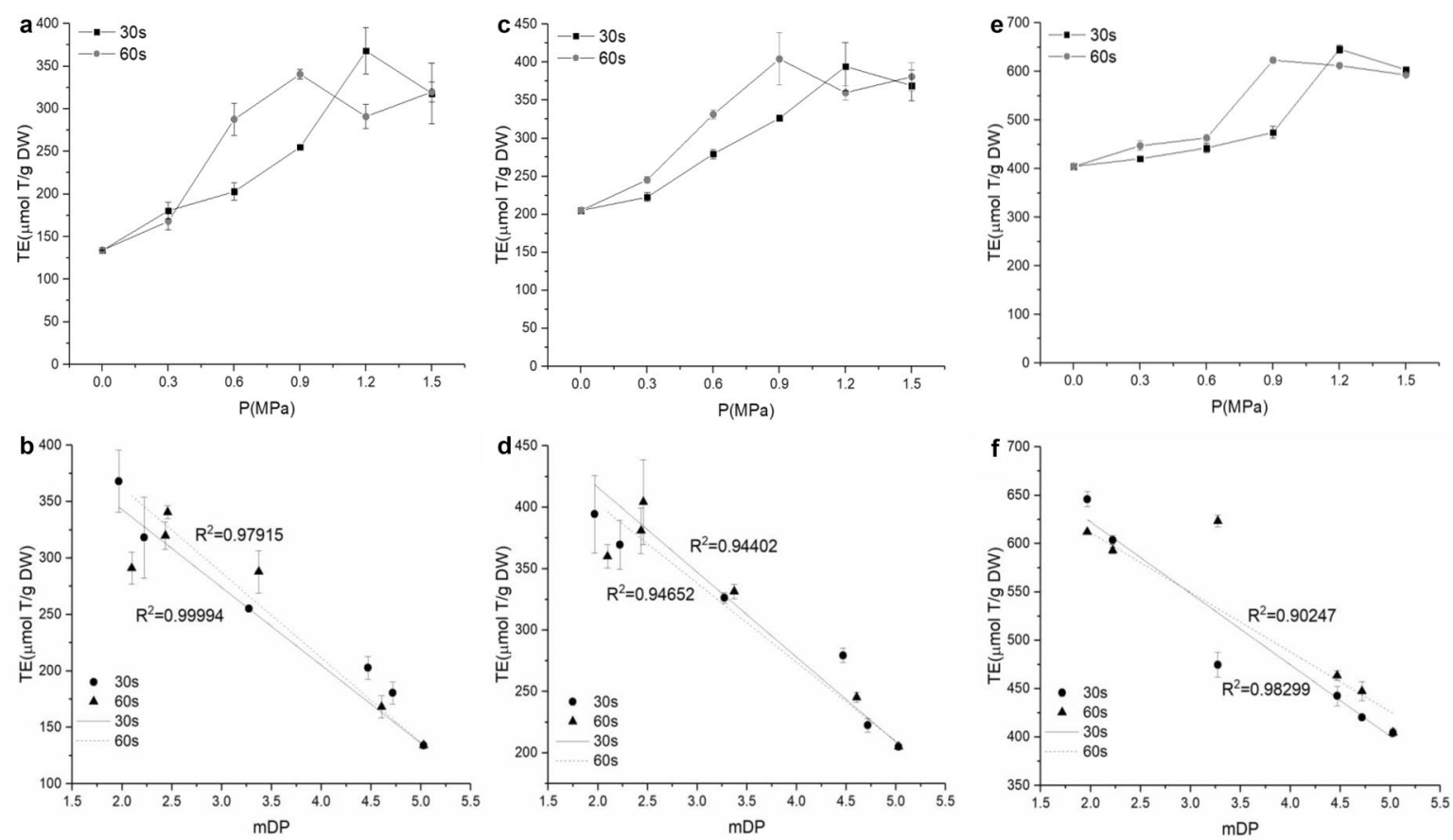

Fig. 3 Antioxidant activity of the extracts with different SE treatments using the method of a DPPH, $\mathbf{c}$ FRAP and e ABTS. The correlation coefficients between $\mathrm{mDP}$ and $\mathbf{b}$ DPPH assay, $\mathbf{d}$ FRAP assay and $\mathbf{f}$ ABTS assay

In unexploded grape seeds, procyanidins with $\mathrm{DP} \geq 5$ accounted for more than $60 \%$ of the total procyanidins (data not shown). After SE treatment, most procyanidins with different DP decreased gradually with the increase of SE severity, especially the procyanidins with DP $>10$ (Fig. 5a, b), while there is a peak at $7.3 \mathrm{~min}$ increasing gradually with the increase of SE severity (Fig. 5a, b, green frame) that was assigned to ECG. Figure $5 \mathrm{c}, \mathrm{d}$ shows the change of peak area growth ratio (PAGR) of procyanidins with different DP after SE treatments, which was used to describe the effect of SE treatment on procyanidins yield. In Fig. 5c, when the 


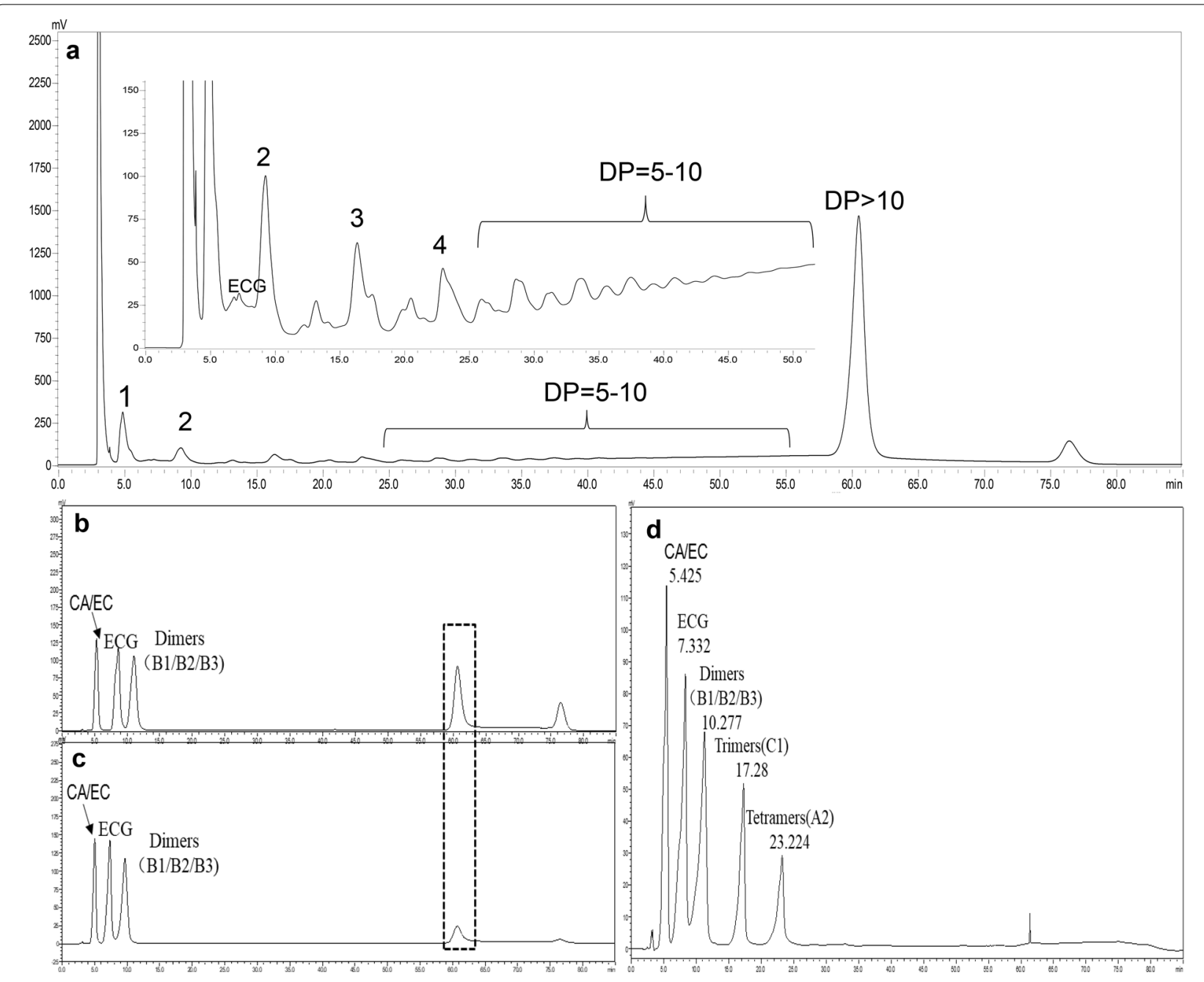

Fig. 4 NP-HPLC chromatogram of unexploded grape seeds extract and mixed standard solutions $(1=$ monomer, $2=$ dimers, $3=$ trimer, $4=$ tetramer) $(\mathbf{a})$; mobile phases $\mathrm{A}=$ acetonitrile/acetic acid $(98: 2, \mathrm{v} / \mathrm{v})(\mathbf{b})$; mobile phases $\mathrm{A}=$ acetonitrile/water $(98: 2, \mathrm{v} / \mathrm{v})(\mathbf{c})$; mixed standard $(\mathrm{CA} /$ $\mathrm{EC}+\mathrm{ECG}+$ Dimers $+\mathrm{C} 1+\mathrm{A} 2)(\mathbf{d})$

pressure was increased from 0.6 to $1.2 \mathrm{MPa}$ with treating time of $30 \mathrm{~s}$, the PAGR of CA/EC increased from 0.81 to 1.54 , and the PAGR of ECG increased from 0.10 to 3.48 , indicating a significant increase of CA/EC and ECG. Nevertheless, when the pressure was increased from 1.2 to $1.5 \mathrm{MPa}$, the increasing trend of the PAGR of CA/EC became slower, while ECG still indicated a higher increasing-rate. The PAGR of procyanidins with $\mathrm{DP} \geq 2$ all indicated a decreasing trend, especially pressures ranging from 0.6 to $1.2 \mathrm{MPa}$. The PAGR of dimers showed a slowest decreasing trend in comparison with trimers, tetramers and polymers with $\mathrm{DP} \geq 5$ (Fig. $5 \mathrm{c}$, d). When treating time was $60 \mathrm{~s}$, the similar results were also observed. These results could be explained by that SE treatment depolymerized the procyanidins to produce monomeric catechins, such as CA, EC and ECG, while lower pressures are not enough to produce them at a large quantity (Fig. 5c, d), which agreed with earlier reports (Gong et al. 2012). It has been reported that SE treatment could degrade the glycoside/ester/ ether bonds in plant tissues to release bioactive phytochemicals, and the degrading degree depended on the type of plant tissues and operating parameters of SE treatment (Gong et al. 2012; Chen and Chen 2011). As a result, it could be speculated that the monomeric catechins (CA, EC and ECG) were derived from the depolymerization of procyanidins. On the other hand, $\mathrm{SE}$ treatment could also degrade procyanidin to form other compounds that were not detected in the present paper.

The inter-flavanol $\mathrm{C}-\mathrm{C}$ bonds in procyanidins are easier to be cleaved by strong acids at room temperature or weak acids at higher temperature (Gu et al. 2004). It has been proved wildly that various organic 

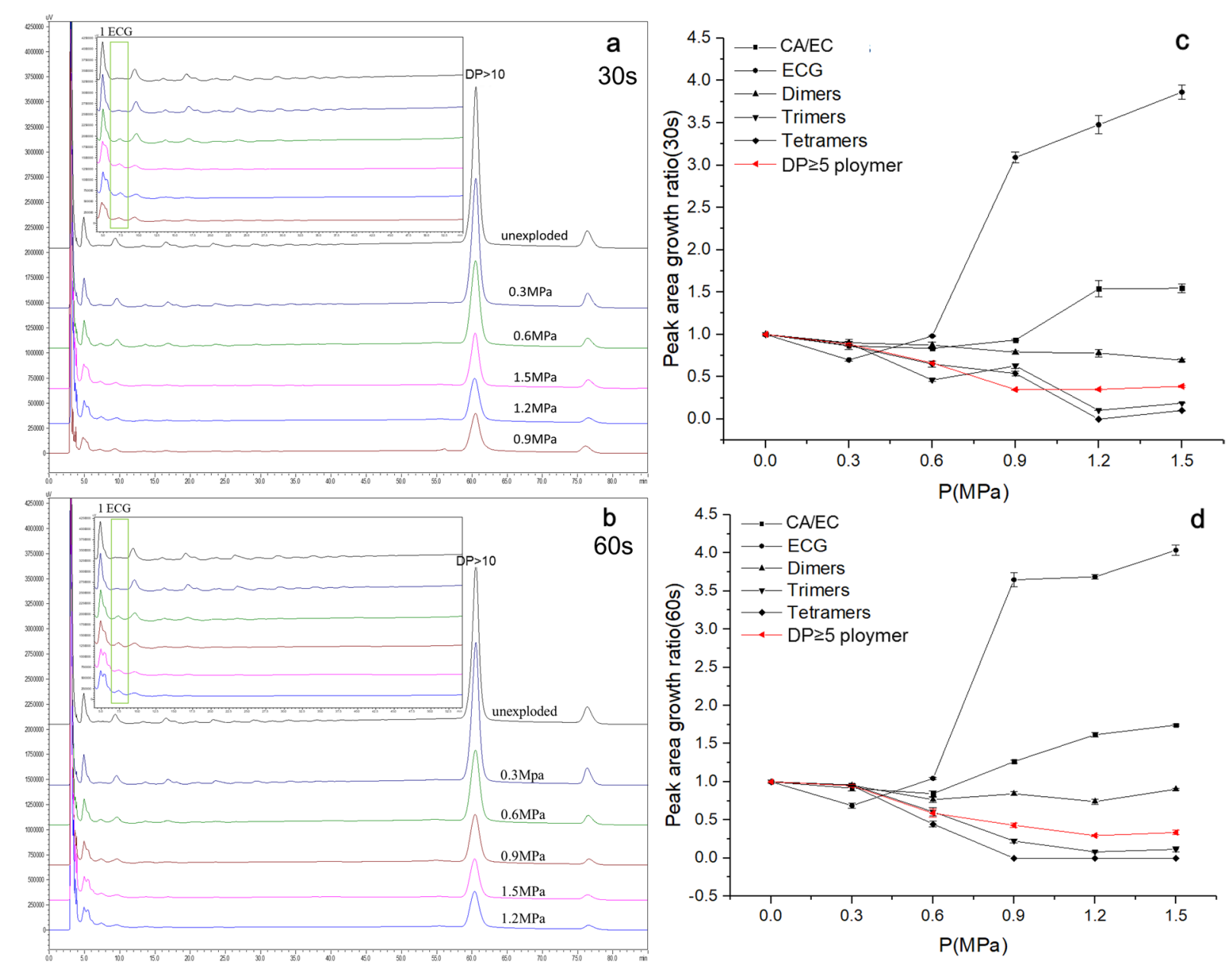

Fig. 5 NP-HPLC chromatogram of procyanidins extracted from unexploded and SE-treated grape seeds $(\mathbf{a}, \mathbf{b})$ and the PAGR of unexploded and SE-treated grape seeds (c, d)

acids were produced after SE treatment, such as levulinic acid, formic acid, acetic acid, etc. (Gong et al. 2012). Figure 5c, d shows that with increase of pressure, the amount of CA/EC and ECG increased and procyanidins with $\mathrm{DP} \geq 2$ decreased. On the basis of NPHPLC results, we inferred that during SE treatment the derived organic acids or hydrogen ions would attack the inter-flavanol $\mathrm{C}-\mathrm{C}$ bonds of PPC at high temperatures (Wojtasz-Mucha et al. 2017), and then CA/EC and ECG were produced from one or both ends of PPC, the inter-flavanol $\mathrm{C}-\mathrm{C}$ bonds of released intermediate procyanidins would be cleaved further resulting in the production of more CA/EC and ECG; additionally, the resultant $\mathrm{CA} / \mathrm{EC}$ and ECG might be degraded further (Additional file 1: Fig. S2). Given the abundant source of PPC in plants, it is possible to produce a large number of catechin monomers from PPC with SE treatment. Therefore, SE treatment is a potential effective method to prepare procyanidins with low degree of polymerization, and high antioxidant activity; however, it is notable that SE treatment could also decrease the yield of total procyanidins in the comparison with the unexploded ones (Fig. 1b, c). Consequently, it still needs to study further how to balance of the yield of total procyanidins and oligomeric procyanidins.

\section{Conclusion}

In this work, it was studied how SE treatment influenced the extraction, depolymerization and antioxidant activities of procyanidins from grape seeds. The results indicated that SE caused the loss of procyanidins and decreased TPC of grape-seeds' extract and $\mathrm{mDP}$ of procyanidins. Nevertheless, antioxidant activity of procyanidins and the yield of CA/EC and ECG increased significantly. Consequently, although SE treatment could depolymerize PPC into catechin monomers with high yield, it caused the loss of total procyanidins. SE 
treatment is a potential effective method to prepared procyanidins with low degree of polymerization and high antioxidant activity. However, it still needs to study further how to balance of the yield of total procyanidins and catechin monomers (CA/EC/ECG).

\section{Abbreviations}

ABTS: 2-20-Azino-di-(3-ethylbenzthiazoline sulfonic acid); CA: Catechin; CE: Catechin equivalents; DM: Dry matter; DP: Degree of polymerization; DPPH: 2,2-Diphenyl-1-picrylhydrazyl hydrate; EC: Epicatechin; ECG: Epicatechin 3-O-gallate; GA: Gallic acid; GAE: Gallic acid equivalents; mDP: Mean degree of polymerization; OPC: Oligomeric procyanidins; PAGR: Peak area of growth ratio; PPC: Polymeric procyanidins; PC: Procyanidin content; SE: Steam explosion; SEM: Scanning electron microscopy; TE: Trolox equivalent; TPC: Total phenolic content; Trolox: 6-Hydroxy-2,5,7,8-tetramethylchroman-2-carboxylic acid.

\section{Supplementary Information}

The online version contains supplementary material available at https://doi. org/10.1186/s40643-021-00376-4.

Additional file 1: Figure S1. NP-HPLC chromatogram of procyanidin standards (a-g) and mixed procyanidin standards (h, i). Figure $\mathbf{S 2}$. Proposed mechanism of PPC depolymerization. Table $\mathbf{S 1}$ Retaining time of procyanidins with different DP in different mobile phase systems. Table S2. The identification and peak assignment of procyanidins units after thiolysis.

\section{Acknowledgements}

The authors are grateful for the financial support received from the National Key Research and Development Program of China (No. 2016YFD0400601) and the National Natural Science Foundation of China (No. 21606014).

\section{Authors' contributions}

WW and $Y Q$ conceived the research. $Z \mathrm{~J}$ and $W W$ designed the experiments. ZJ conducted the experiments. WA, CL and US participated in helping ZJ to complete the relevant experiments. LY gave some guidance to the experiments. WW finalized the manuscript with assistance from LD. All authors read and approved the final manuscript.

\section{Funding}

This work was supported by the National Key Research and Development Program of China (No. 2016YFD0400601) and the National Natural Science Foundation of China (No. 21606014).

\section{Availability of data and materials}

They are included within the article and its Additional files.

\section{Declarations}

Ethics approval and consent to participate

Not applicable.

\section{Consent for publication}

Not applicable.

\section{Competing interests}

The authors declare no competing financial interests.

\section{Author details}

${ }^{1}$ College of Life Science and Technology, Beijing University of Chemical Technology, Beijing 100029, China. ${ }^{2}$ Amoy-BUCT Industrial Biotechnovation Institute, Beijing University of Chemical Technology, Amoy 361022, China.
Received: 20 November 2020 Accepted: 12 March 2021

Published online: 23 March 2021

\section{References}

Alvira P, Tomás-Pejó E, Ballesteros M, Negro MJ (2010) Pretreatment technologies for an efficient bioethanol production process based on enzymatic hydrolysis: a review. Bioresource Technol 101(13):4851-4861

Bordiga M, Travaglia F, Locatelli M, Coïsson JD, Arlorio M (2011) Characterisation ofpolymeric skin and seed proanthocyanidins during ripening in six Vitis vinifera L. CV. Food Chem 127(1):180-187

Çam M, Hışı| Y (2010) Pressurised water extraction of polyphenols from pomegranate peels. Food Chem 123(3):878-885

Carvalheiro F, Duarte LC, Gírio FM (2008) Hemicellulose biorefineries: a review on biomass pretreatments. J Sci Ind Res India 67(11):849-864

Chen G, Chen H (2011) Extraction and deglycosylation of flavonoids from sumac fruits using steam explosion. Food Chem 126(4):1934-1938

Chen W, Fu C, QinY HD (2009) One-pot depolymerizative extraction of proanthocyanidins from mangosteen pericarps. Food Chem 114(3):874-880

Choy YY, Jaggers GK, Oteiza PI, Waterhouse AL (2013) Bioavailability of intact proanthocyanidins in the rat colon after ingestion of grape seed extract. Agr Food Chem 61(1):121-127

Conde E, Cara C, Moure A, Ruiz E, Castro E, Domínguez H (2009) Antioxidant activity of the phenolic compounds released by hydrothermal treatments of olive tree pruning. Food Chem 114(3):806-812

Furuuchi R, Yokoyama T, Watanabe Y, Hirayama M (2011) Identification and quantification of short oligomeric proanthocyanidins and other polyphenols in boysenberry seeds and juice. J Agr Food Chem 59(8):3738-3746

Gong L, Huang L, Zhang Y (2012) Effect of steam explosion treatment on barley bran phenolic compounds and antioxidant capacity. J Agr Food Chem 60(29):7177-7184

Gu L, Kelm M, Hammerstone JF, Beecher G, Cunningham D, Vannozzi S, Prior RL (2002) Fractionation of polymeric procyanidins from lowbush blueberry and quantification of procyanidins in selected foods with an optimized normal-phase HPLC-MS fluorescent detection method. J Agr Food Chem 50(17):4852-4860

Gu L, Kelm MA, Hammerstone JF, Beecher G, Holden J, Haytowitz D, Prior RL (2004) Concentrations of proanthocyanidins in common foods and estimations of normal consumption. J Nutr 134(3):613-617

Hayasaka Y, Waters EJ, Cheynier V, Herderich MJ, Vidal S (2003) Characterization of proanthocyanidins in grape seeds using electrospray mass spectrometry. Rapid Commun Mass Sp 17(1):9-16

Hellström JK, Mattila PH (2008) HPLC determination of extractable and unextractable proanthocyanidins in plant materials. J Agr Food Chem 56(17):7617-7624

Hümmer W, Schreier P (2010) Analysis of proanthocyanidins. Mol Nutr Food Res 52:1381-1398

Ito C, Oki T, Yoshida T, Nanba F, Yamada K, Toda T (2013) Characterisation of proanthocyanidins from black soybeans: Isolation and characterisation of proanthocyanidin oligomers from black soybean seed coats. Food Chem 141(3):2507-2512

Jacquet N, Maniet G, Vanderghem C, Delvigne F, Richel A (2015) Application of steam explosion as pretreatment on lignocellulosic material: a review. Ind Eng Chem Res 54(10):2593-2598

Li L, Zhang S, Cui Y, Li Y, Luo L, Zhou P, Sun B (2016) Preparative separation of cacao bean procyanidins by high-speed counter-current chromatography. J Chromatog B 1036:10-19

Li Z, Zeng J, Tong Z, Qi Y, Gu L (2015) Hydrogenolytic depolymerization of procyanidin polymers from hi-tannin sorghum bran. Food Chem 188:337-342

Lin Q, Cao Q, Huo Q (2014) Study on Degradation process of procyanidins. Asian J Chem 26(19):6665-6668

Liu H, Zou T, Gao JM, Gu L (2013) Depolymerization of cranberry procyanidins using (+)-catechin, (-)-epicatechin, and (-)-epigallocatechin gallate as chain breakers. Food Chem 141(1):488-494

Luo L, Cui Y, Zhang S, Li L, Li Y, Zhou P, Sun B (2016) Preparative separation of grape skin polyphenols by high-speed counter-current chromatography. Food Chem 212:712-721 
Luo L, CuiY, Cheng J, Fang B, Wei Z, Sun B (2018) An approach for degradation of grape seed and skin proanthocyanidin polymers into oligomers by sulphurous acid. Food Chem 256:203-211

Matthews S, Mila I, Scalbert A, Pollet B, Lapierre C, Catherine LM, Donnelly DM (1997) Method for estimation of proanthocyanidins based on their acid depolymerization in the presence of nucleophiles. J Agr Food Chem 45(4):1195-1201

Meeran SM, Katiyar SK (2007) Grape seed proanthocyanidins promote apoptosis in human epidermoid carcinoma A431 cells through alterations in Cdki-Cdk-cyclin cascade, and caspase - 3 activation via loss of mitochondrial membrane potential. Exp Dermatol 16(5):405-415

Monagas M, Quintanilla-López JE, Gómez-Cordovés C, Bartolomé B, LebrónAguilar R (2010) MALDI-TOF MS analysis of plant proanthocyanidins. J Pharmaceut Biomed 51(2):358-372

Oldoni TLC, Melo PS, Massarioli AP, Moreno IAM, Bezerra RMN, Rosalen PL, Silva GVJD, Nascimento AM, Alencar SM (2016) Bioassay-guided isolation of proanthocyanidins with antioxidant activity from peanut (Arachis hypogaea) skin by combination of chromatography techniques. Food Chem 192:306-312

Ou K, Gu L (2014) Absorption and metabolism of proanthocyanidins. J Funct Foods 7:43-53

Porter LJ (1988) Flavans and proanthocyanidins. In: Harborne JB (ed) The flavonoids advances in research since 1980. Chapman and Hall, London and New York, pp 21-62

Prieur C, Rigaud J, Cheynier V, Moutounet M (1994) Oligomeric and polymeric procyanidins from grape seeds. Phytochemistry 36(3):781-784

Qin L, Chen H (2015) Enhancement of flavonoids extraction from fig leaf using steam explosion. Ind Crop Prod 69:1-6

Serrano A, Fermoso FG, Alonso-Fariñas B, Rodríguez-Gutierrez G, FernandezBolaños J, Borja R (2017) Phenols recovery after steam explosion of Olive Mill Solid Waste and its influence on a subsequent biomethanization process. Bioresource Technol 243:169-178

Silvan JM, Gutiérrez-Docio A, Moreno-Fernandez S, Alarcón-Cavero T, Prodanov M, Martinez-Rodriguez AJ (2020) Procyanidin-rich extract from grape seeds as a putative tool against helicobacter pylori. Foods 9(10):1370

Souquet JM, Cheynier V, Brossaud F, Moutounet M (1996) Polymeric proanthocyanidins from grape skins. Phytochemistry 43(2):509-512

Spranger I, Sun B, Mateus AM, Freitas VD, Ricardo-da-Silva JM (2008) Chemical characterization and antioxidant activities of oligomeric and polymeric procyanidin fractions from grape seeds. Food Chem 108(2):519-532

Sun B, Neves AC, Fernandes TA, Fernandes AL, Mateus N, De Freitas V, Leandro C, Spranger MI (2011) Evolution of phenolic composition of red wine during vinification and storage and its contribution to wine sensory properties and antioxidant activity. J Agr Food Chem 59(12):6550-6557
Unusan N (2020) Proanthocyanidins in grape seeds: An updated review of their health benefits and potential uses in the food industry. J Funct Foods 67:103861

Vivas N, Nonier MF, De Gaulejac NV, Absalon C, Bertrand A, Mirabel M (2004) Differentiation of proanthocyanidin tannins from seeds, skins and stems of grapes (Vitis vinifera) and heartwood of Quebracho (Schinopsis balansae) by matrix-assisted laser desorption/ionization time-of-flight mass spectrometry and thioacidolysis/liquid chromatography/electrospray ionization mass spectrometry. Anal Chim Acta 513(1):247-256

Wang S, Ouyang X, Wang W, Yuan Q, Yan A (2016) Comparison of ultrasoundassisted Fenton reaction and dilute acid-catalysed steam explosion pretreatment of corncobs: cellulose characteristics and enzymatic saccharification. RSC Adv 6(80):76848-76854

White BL, Howard LR, Prior RL (2010) Release of bound procyanidins from cranberry pomace by alkaline hydrolysis. J Agr Food Chem 58(13):7572-7579

Wojtasz-Mucha J, Hasani M, Theliander H (2017) Hydrothermal pretreatment of wood by mild steam explosion and hot water extraction. Bioresource Technol 241:120-126

Wu Z, Zhu X, Guo H, Jiang Y, Gu X (2019) A kinetic study of lignin pyrolysis over base catalyst during steam exploded depolymerization. Catal Today 327:226-234

Xia Q, Wang L, Xu C, Mei J, Li Y (2017) Effects of germination and high hydrostatic pressure processing on mineral elements, amino acids and antioxidants in vitro bioaccessibility, as well as starch digestibility in brown rice (Oryza sativa L.). Food Chem 214:533-542

Xu C, Yagiz Y, Borejsza-Wysocki W, Lu J, Gu L, Ramírez-Rodrigues MM, Marshall MR (2014) Enzyme release of phenolics from muscadine grape (Vitis rotundifolia Michx.) skins and seeds. Food Chem 157:20-29

Zhang HJ, Fan XG, Qiu XL, Zhang QX, Wang WY, Li SX, Yuan QP (2014) A novel cleaning process for industrial production of xylose in pilot scale from corncob by using screw-steam-explosive extruder. Bioproc Biosyst Eng 37(12):2425-2436

Zhang S, Cui Y, Li L, Li Y, Zhou P, Luo L, Sun B (2015a) Preparative HSCCC isolation of phloroglucinolysis products from grape seed polymeric proanthocyanidins as new powerful antioxidants. Food Chem 188:422-429

Zhang Y, Zhao W, Yang R (2015b) Steam flash explosion assisted dissolution of keratin from feathers. ACS Sustain Chem Eng 3(9):2036-2042

\section{Publisher's Note}

Springer Nature remains neutral with regard to jurisdictional claims in published maps and institutional affiliations.

\section{Submit your manuscript to a SpringerOpen ${ }^{\circ}$ journal and benefit from:}

- Convenient online submission

- Rigorous peer review

- Open access: articles freely available online

- High visibility within the field

- Retaining the copyright to your article

Submit your next manuscript at $\boldsymbol{\nabla}$ springeropen.com 